\title{
An Intervention to Improve Motivation for Homework
}

\author{
Elisabeth Akioka and Linda Gilmore \\ Queensland University of Technology, Brisbane, Australia
}

\begin{abstract}
A repeated measures design, with randomly assigned intervention and control groups and multiple sources of information on each participant, was used to examine whether changing the method of delivery of a school's homework program in order to better meet the students' needs for autonomy, relatedness and competence would lead to more positive student attitudes to homework, and whether there would also be a positive change in overall motivation. The participants were 104 male students aged 10 to 12 years who attended a single sex high school. There was no overall intervention effect on motivation; however, the intervention appeared to have a protective effect on the quality of motivation.
\end{abstract}

Keywords: homework, motivation, self-determination theory, intervention

There are two contrasting views about homework. On one side of the debate are those who call for homework to be reduced or reformed, pointing to its negative family impact, capacity to entrench ability and socioeconomic differences, and limited value for academic achievement (Horsley \& Walker, 2013; Kohn, 2006; Trautwein, Köller, Schmitz \& Baumert, 2001). On the other side are those who cite positive associations between homework and academic achievement (Cooper, Lindsay, Nye, \& Greathouse, 1998; Cooper \& Valentine, 2001; Marzano \& Pickering, 2007).

It is clear that homework potentially has both costs and benefits, so is it possible to increase children's access to the benefits while reducing their exposure to the costs? The benefits of homework are available only to those children who actually do their homework (Cooper, Valentine, Nye, \& Lindsay, 1999). Similarly, family conflict over homework reduces sharply if children do not resist completing homework (Kohn, 2006). Thus, the problem is how to create a situation in which children do their homework willingly. The answer may lie in the significant body of research on motivation.

Self-determination theory (SDT; Deci \& Ryan, 2000, 2008) provides a conceptual framework for exploring motivation in contexts such as schools. SDT proposes

ADDRESS FOR CORRESPONDENCE: Linda Gilmore, School of Learning and Professional Studies, Queensland University of Technology, Victoria Park Road, Kelvin Grove QLD 4059, Australia. Email: l.gilmore@qut.edu.au 
a continuum of motivation styles from intrinsic (fully internally motivated), through identification (a mostly internal motivation style indicated by conscious externalgoal endorsement) and introjection (a mostly external motivation style indicated by a need for approval from others) to extrinsic (fully externally motivated; Ryan \& Connell, 1989). Vansteenkist, Sierens, Soenens, Luyckx, and Lens (2009) confirmed the presence of the four motivational profiles suggested by SDT in a school environment and further confirmed that the more motivation tends toward the intrinsic end of the SDT continuum, the better effect it has on student outcomes.

SDT proposes that motivation is driven by core underlying psychological needs for autonomy, relatedness and competence (Deci \& Ryan, 2000, 2008). Autonomy refers to volition and the desire to organise one's own experience and behaviour; relatedness refers to the need for secure attachments; and competence is the need for (positive) information about satisfactory performance on an activity. The factors affecting each of these psychological needs in educational settings have been the subject of considerable research. Autonomy support is sometimes completely conflated with offering choice; however, work by Katz and Assor (2007) found that only choices that were relevant to student interests were effectively supportive of autonomy. Further, a range of strategies beyond choice are also supportive of autonomy. Black and Deci (2000) found that teachers' autonomy support increased students' overall motivation and specifically increased their sense of autonomy and perceived competence. Earlier work by Grolnick, Kurowski and Gurland (1999) indicated that autonomy supportive environments shared a set of specific features: problem-solving was encouraged, the environment was structured and predictable, and emotional resources were provided to students.

Deci and Ryan (2000) linked relatedness directly to attachment - the bond between a child and his or her primary caregiver, so meeting such a need in an educational context may seem difficult; however, research by Hetherington (1993) found that school environments could be classified into types that strongly paralleled those found in parenting styles literature: authoritative, authoritarian, permissive and chaotic/neglecting. As with parenting styles, school environments that were authoritative (i.e., high on responsiveness to students, with high expectations of students within a stable, predictable environment) were associated with better student outcomes.

Patrick, Kaplan, and Ryan (2011) found that classroom environment predicted whether students endorsed mastery goals (success is accompanied by effort and is indicated by personal improvement or achievement of a set standard) or performance goals (learning is a means of achieving recognition of personal worth and success is indicated by outperforming others). Classroom environments that promote a mastery orientation successfully meet the need for competence of all students; however, class environments that promote a performance orientation better meet the need for competence of the highest achieving students and can have a negative impact on lower achieving students (Patrick et al., 2011). Competence is related not only to classroom environment, but also to the nature and frequency of feedback (Levesque, Zuehlke, Stanek, \& Ryan, 2004). In a study comparing German and US college students, Levesque et al. (2004) found that high frequency feedback, even when it was of low quality (grades without comments), led to higher feelings of competence than very infrequent, but high quality feedback. 
Given the well-established relationship between effective support for the psychological needs of autonomy, relatedness and competence and increases in motivation, as well as a small amount of evidence suggesting that teacher support may be important particularly for homework motivation (Katz, Kaplan, \& Gueta, 2010), we hypothesised that a homework program specifically designed to address these needs would lead to an increase in homework-specific motivation, a decrease in homework-related distress, and possibly also an increase in overall motivation. Surprisingly, few homework interventions have been documented in the literature. Difficulties with homework completion have tended to be viewed as behavioural issues that require a behavioural intervention, using strategies such as self-management (e.g., Axelrod, Zhe, Haugen, \& Klein, 2009) and positive reinforcement (Theodore et al., 2009). Another goal of homework interventions has been to increase parental involvement in children's homework (e.g., Frolland, 2011; Haas \& Reiley, 2008; Van Voorhis, 2011). In a small study $(n=15)$, Frolland (2011) taught parents how to support their young child's autonomy with homework (e.g., by setting goals independently) and reported positive benefits for children's subsequent homework-related affect, but no overall improvements in academic motivation or autonomy. Drawing on SDT theory, Patall, Cooper, and Wynn (2010) found that high school students who were offered choice in their homework assignments reported higher motivation for homework, completed a greater amount of homework, and perceived themselves to be more competent than did a control group. However, students in the intervention group did not make more effort with their homework, nor did they report decreased levels of stress associated with homework.

The current homework intervention was designed to incorporate not only support for autonomy through the provision of choice among homework options, but also a focus on encouraging relatedness through an increase in both peer and student-teacher interactions, and developing competence through personalised feedback. Thus, all three components of SDT were included in the intervention.

\section{Method}

\section{Participants}

The participants were 104 students (mean age $=11.2$ years, $S D=0.5$, range 10 to 12 years) who were enrolled in four Year 7 classes at a private boys' school in Brisbane, Australia. Four class teachers also participated. The research was initiated by staff at the school, and students were given the opportunity to decline to participate. All took part in the study. Parents were also invited to complete online questionnaires. However, because only 12 parents from the 104 families responded, these data were not included in analyses.

\section{Instruments}

Children's Attitude to Homework Questionnaire (CAHQ). The Children's Attitude to Homework Questionnaire (CAHQ) (Gilmore, 2007) is a 22-item questionnaire designed to assess homework habits and attitudes to homework. There is a student version and a parent version. The CAHQ consists of a range of multiple choice, Likert-scaled and open response items. It is intended to gather information about 
the frequency and nature of homework, attitudes to homework, the influence of homework on child-parent interactions, and a student's general attitude towards school.

Dimensions of Mastery Questionnaire (DMQ-17). The Dimensions of Mastery Questionnaire (DMQ-17; Morgan, Busch-Rossnagel, Barrett, \& Wang, 2009) is a 45 -item questionnaire that provides ratings of motivation. All responses are on a Likert scale from 1 (not at all typical) to 5 (very typical). Items load onto six motivation subscales: Persistence on Cognitive Tasks, Gross Motor Persistence, Social Persistence with Adults, Social Persistence with Children, Mastery Pleasure, and Negative Reactions to Failure, as well as a General Competence subscale. The General Competence and Gross Motor Persistence subscales were not used in the current study. There is a DMQ version for parents to report on their child's motivation, as well as a child self-report for older children and adolescents. In the current study, to create a teacher version the parent DMQ was modified slightly (instruction wording 'your child' was changed to 'this student').

\section{Study Design and Procedure}

The study examined a modified homework program through a repeated measures design with randomly assigned intervention and control groups and multiple sources of information on each participant. The entire Year 7 cohort participated in the study. The four existing class groupings were used as these were not streamed or academically stratified in any way. Two classes were randomly assigned to the intervention condition $(n=52)$ and two were allocated to the control condition $(n=52)$. Class teachers were shared between the pairs of classes in each condition, but only one teacher completed measures on each class.

Pre-intervention measures were taken at the end of the first 10-week term of the school year. Students completed the CAHQ and the DMQ in an online format during class time. For each student, one class teacher completed the DMQ. Parents were invited to complete the CAHQ in an online format via the school's website.

The intervention, described below, was implemented for the whole of the second term (10 weeks). During this time control group classes adhered to the school's usual homework program. Questionnaires (CAHQ and DMQ) were then readministered online to all students early in the third term, and class teachers completed the DMQ for each student. Parents were again invited to complete the CAHQ.

\section{Intervention Design}

The intervention was designed to incorporate elements that have been linked consistently to higher student motivation for learning: autonomy, relatedness and competence (Ryan \& Deci, 2000). One of the researchers (the first author) collaborated with the Head of Curriculum to modify the school's usual homework program in the areas of English, Maths, Science, and Studies of Society and Environment. Students in the intervention group also participated in one lesson conducted by a teacher in the first week of the intervention that was designed to link the skills acquired through homework with the achievement of later life goals.

Autonomy was targeted through the provision of more choice in the homework program. For example, in English, students were given the opportunity to 
choose between 'standard' and 'creative' versions of the same task; maths problems could be 'standard' or 'challenge' (i.e., standard drill practice of maths problems, or complex applied problems that required the use of appropriate mathematical procedures), and different response mediums were available (e.g., written, visual, digital). Relatedness was emphasised both between students and adults, and between students and their peers. The Studies of Society and Environment/English teacher scheduled open consultation times during specific lunch breaks for students to be able to access his support and guidance with larger homework-based assignments. Students were also encouraged to use each other as resources during these sessions. The Maths/Science teacher established and promoted an online bulletin board to enable the boys to seek peer help with homework tasks. This teacher also paired students of different maths ability and encouraged the pairs to help each other with homework exercises and preparation for assessment. The focus on competence was achieved through more frequent and more personalised feedback on high-volume, rote homework tasks (maths drills, grammar exercises) which were previously checked only for completion, not accuracy.

\section{Results}

\section{Preliminary Analyses}

One teacher was unavailable to respond to the post-intervention DMQs for his students, and these questionnaires were completed by one of the other class teachers. Preliminary analyses indicated significant differences on all DMQ subscales for this group. As the differences were considered likely to be an unintended artefact of the change in assessor, the teacher data for this entire class were excluded from subsequent analysis.

\section{Children's Attitude to Homework Questionnaire (CAHQ)}

An initial principal component analysis was conducted on the 22-item CAHQ. In order to facilitate this, open-ended items were recoded to a 5-point Likert scale. Items with a Likert scale and an 'other' option had all 'other' responses recoded to the Likert scale based on the content of the associated comment. Two preintervention and two post-intervention responses were recoded for 'How often do you do homework?' Eleven pre-intervention and 11 post-intervention responses were recoded for 'How much homework do you get?' Eight components with eigenvalues greater than one were identified in the initial PCA. Of these, five components had two or fewer items loading. Ten low- and cross-loading items were removed, and a further principal component analysis with oblique rotation was conducted separately for pre- and post-intervention responses on the remaining 12 items, with a forced three-factor solution.

The factor structure (see Table 1) converged in six iterations for pre-intervention responses and eight iterations for post-intervention responses, and resulted in identical groupings of items. The three components were labelled 'Homework Conflict', 'Homework Engagement' and 'Homework Difficulty', based on high scores on the constituent items. Using Cronbach's alpha, internal consistencies were calculated separately for each of the three subscales for pre- and post-intervention. These were considered good to acceptable: Homework Conflict (pre-intervention $=.81$; 


\section{TABLE 1}

Factor Structure of the Children's Attitude to Homework Questionnaire at Pre- and Post-Intervention

\begin{tabular}{|c|c|c|c|}
\hline Item & $\begin{array}{l}\text { Homework } \\
\text { Conflict }\end{array}$ & $\begin{array}{l}\text { Homework } \\
\text { Engagement }\end{array}$ & $\begin{array}{l}\text { Homework } \\
\text { Difficulty }\end{array}$ \\
\hline $\begin{array}{l}\text { How often do you have arguments at home about your } \\
\text { homework? }\end{array}$ & $.81(.74)$ & & \\
\hline $\begin{array}{l}\text { How often do you have fights at home about your } \\
\text { homework? }\end{array}$ & $.90(.66)$ & & \\
\hline How often do your parents get upset about your homework? & $.78(.80)$ & & \\
\hline How often do you become upset about your homework & $.71(.77)$ & & \\
\hline $\begin{array}{l}\text { Do you think your teacher gives you: too much homework / } \\
\text { about the right amount / not enough }\end{array}$ & & $-.48(.69)$ & \\
\hline How often do you complete your set homework? & & $-.57(.48)$ & \\
\hline How often do you find homework interesting? & & $-.75(.75)$ & \\
\hline How often do you find homework boring? (Reverse coded) & & $-.72(.63)$ & \\
\hline $\begin{array}{l}\text { Please indicate how much you like school: I hate school/I do } \\
\text { not like school much / I neither like nor dislike school / } \\
\text { I usually like school / I really love school }\end{array}$ & & $-.78(.72)$ & \\
\hline $\begin{array}{l}\text { Generally, do you find homework: way too easy / quite easy / } \\
\text { neither easy nor hard/ quite hard / way too hard }\end{array}$ & & & $.82(-.81)$ \\
\hline How often do you find homework challenging? & & & $.92(-.84)$ \\
\hline How often does an adult help you with your homework? & & & $.66(-.40)$ \\
\hline
\end{tabular}

Note: Post-intervention loadings in brackets.

post-intervention $=.76$ ), Homework Engagement (pre-intervention $=.70$; postintervention $=.66$ ) and Homework Difficulty (pre-intervention $=.75$; postintervention $=.61$ ). The total variance explained for the retained factors was $59.37 \%$ for the pre-intervention responses and $55.34 \%$ for the post-intervention responses.

A repeated measures MANOVA was conducted with the two-level WithinSubject factor Time (Pre-intervention and Post-intervention), the two-level Between-Subjects factor Group (Intervention and Control), and the three CAHQ subscales as the repeated measures. Assumptions were met after one univariate outlier was filtered out and a reciprocal transformation of the Homework Conflict scores was undertaken.

There was a significant main effect for Time, $F(3,69)=2.73, p=.05$; Wilks' Lambda $=.894$; partial eta squared $=.11$, observed power $=.64$. However, there was no main effect for Group, or interaction between Group and Time. Posthoc univariate analysis indicated that Homework Difficulty decreased over time, $F(1,71)=5.70, p=.02$, partial eta squared $=.07$, observed power $=.65$. See Tables 2 and 3 for means and standard deviations of the three CAHQ subscales in the two groups.

Each student's relative intrinsic-extrinsic motivation for homework was assessed using two open-ended questions on the CAHQ: 'Why do you think teachers give you homework?' 'What do you perceive to be the benefits of homework?' Based on their content, responses were coded into a 5-level Likert scale that aligned with Deci 
TABLE 2

Means and Standard Deviations of CAHQ subscales: Intervention Group

\begin{tabular}{|c|c|c|c|c|c|c|c|c|}
\hline \multirow[b]{2}{*}{ Subscale } & \multicolumn{4}{|c|}{ Time 1} & \multicolumn{4}{|c|}{ Time 2} \\
\hline & Range & $n$ & $M$ & $S D$ & Range & $n$ & $M$ & $S D$ \\
\hline Homework Conflict & $4-20$ & 51 & 6.92 & 3.74 & $4-14$ & 41 & 5.71 & 2.26 \\
\hline Homework Engagement & $8-21$ & 51 & 15.16 & 2.88 & $9-20$ & 41 & 15.49 & 2.73 \\
\hline Homework Difficulty & $3-14$ & 49 & 8.51 & 2.36 & $4-11$ & 41 & 8.22 & 1.75 \\
\hline
\end{tabular}

TABLE 3

Means and Standard Deviations of CAHQ Subscales: Control Group

\begin{tabular}{|c|c|c|c|c|c|c|c|c|}
\hline \multirow[b]{2}{*}{ Subscale } & \multicolumn{4}{|c|}{ Time 1} & \multicolumn{4}{|c|}{ Time 2} \\
\hline & Range & $n$ & $M$ & $S D$ & Range & $n$ & $M$ & $S D$ \\
\hline Homework Conflict & $4-10$ & 43 & 5.81 & 1.72 & $4-12$ & 46 & 6.11 & 2.19 \\
\hline Homework Engagement & $7-21$ & 42 & 14.57 & 3.39 & $9-20$ & 44 & 15.00 & 2.75 \\
\hline Homework Difficulty & $4-13$ & 43 & 8.33 & 1.87 & $4-13$ & 46 & 7.96 & 1.87 \\
\hline
\end{tabular}

\section{TABLE 4}

Key to Coding of Open-ended Responses into Motivation Types

\begin{tabular}{|c|c|c|c|}
\hline Code & Description & Key concepts & Sample responses \\
\hline 1 & Extrinsic & Focus on negatives & $\begin{array}{l}\text { 'So they don't have to teach you.' 'I see no benefit.' } \\
\text { 'The only thing homework teaches you is how to } \\
\text { do homework.' }\end{array}$ \\
\hline 2 & Introjected & $\begin{array}{l}\text { Extra work/cover } \\
\text { more/things missed } \\
\text { in class, Revise (short } \\
\text { term) }\end{array}$ & $\begin{array}{l}\text { 'It helps you revise for the next day.' 'It helps you set } \\
\text { in the work of the day.' }\end{array}$ \\
\hline 3 & Identified & $\begin{array}{l}\text { Remember (long term) } \\
\text { Learn (more) }\end{array}$ & $\begin{array}{c}\text { '... that we remember things more clearly and you } \\
\text { know, method to do things.' } \ldots \text { to get smart.' }\end{array}$ \\
\hline 4 & Integrated & $\begin{array}{l}\text { Independent learning } \\
\text { Future, Helpful later } \\
\text { in life }\end{array}$ & $\begin{array}{l}\text { 'I think we have homework so we can do good later } \\
\text { in our lives.' 'Our brain is always learning, which } \\
\text { helps us become better people.' 'You will learn } \\
\text { important things that will help you in future years } \\
\text { of work.' }\end{array}$ \\
\hline 5 & Intrinsic & Enjoyment & 'Fun!' \\
\hline
\end{tabular}

and Ryan's (2000) levels of motivation. Each level of motivation was associated with a set of key concepts, responses were assessed against the key concepts, and then coded based on the dominant concepts present. The coding of key responses in terms of levels of motivation is detailed in Table 4.

A repeated measures MANOVA was conducted with the two-level WithinSubject factor Time (Pre-intervention and Post-intervention), the two-level Between-Subjects factor Group (Intervention and Control), and the two measures of intrinsic-extrinsic motivation as the repeated measures. Assumptions were met 


\section{TABLE 5}

Means and Standard Deviations of Intrinsic-Extrinsic Motivation Items: Intervention Group

\begin{tabular}{|c|c|c|c|c|c|c|c|c|}
\hline \multirow[b]{2}{*}{ Item } & \multicolumn{4}{|c|}{ Time 1} & \multicolumn{4}{|c|}{ Time 2} \\
\hline & Range & $n$ & $M$ & $S D$ & Range & $n$ & $M$ & $S D$ \\
\hline Why do you think teachers give you homework? & $1-4$ & 50 & 2.34 & 0.82 & $1-4$ & 41 & 2.56 & 0.78 \\
\hline $\begin{array}{l}\text { What do you perceive to be the benefits of } \\
\text { homework? }\end{array}$ & $1-4$ & 50 & 2.28 & 0.88 & $1-4$ & 41 & 2.71 & 0.68 \\
\hline
\end{tabular}

\section{TABLE 6}

Means and Standard Deviations of Intrinsic-Extrinsic Motivation Items: Control Group

\begin{tabular}{|c|c|c|c|c|c|c|c|c|}
\hline \multirow[b]{2}{*}{ Item } & \multicolumn{4}{|c|}{ Time 1} & \multicolumn{4}{|c|}{ Time 2} \\
\hline & Range & $n$ & M & $S D$ & Range & $n$ & M & $S D$ \\
\hline Why do you think teachers give you homework? & $1-4$ & 43 & 2.37 & 0.87 & 46 & $1-4$ & 2.65 & 0.82 \\
\hline $\begin{array}{l}\text { What do you perceive to be the benefits of } \\
\text { homework? }\end{array}$ & $1-4$ & 43 & 2.47 & 1.12 & 46 & $1-5$ & 2.85 & 0.87 \\
\hline
\end{tabular}

after a $\log$ transformation of the four variables was undertaken. There was a significant main effect for Time, $F(2,74)=9.16, p<.001$; Wilks' Lambda $=.802$; partial eta squared $=.20$, observed power $=.97$, but there was no main effect for Group, and no significant interaction between Group and Time. Post-hoc univariate analysis showed that perceptions of the benefits of homework were framed in more intrinsic terms over time, $F(1,74)=15.96, p<.001$, partial eta squared $=$ .18 , observed power $=.98$. See Tables 5 and 6 for means and standard deviations of intrinsic-extrinsic motivation items.

A measure of change in motivation was calculated by averaging each student's coded response to the two intrinsic-extrinsic motivation items, and subtracting the score at pre-intervention from the score at post-intervention. Changes in motivation by group are shown in Table 7 . The Control group displayed more change in motivation overall as only $28.9 \%$ of this group experienced no change in motivation, compared with $61.5 \%$ of the intervention group. The Control group experienced $18.4 \%$ negative change in motivation, compared with $0 \%$ for the Intervention group, and $52.7 \%$ positive change, compared with $38.5 \%$ for the Intervention group. On this measure a negative change in motivation means a shift towards a more extrinsic / less intrinsic style of motivation and a positive change in motivation means a shift towards a more intrinsic / less extrinsic style.

\section{Dimensions of Mastery Questionnaire (DMQ)}

Internal consistencies were calculated for all subscales using Cronbach's alpha. Values ranged from .55 (Negative Reactions to Failure) to .81 (Mastery Pleasure) for student self-reports, and from .59 (Social Persistence with Children) to .92 (Mastery Pleasure and Persistence at Cognitive Tasks) for teacher ratings. Scale pairs with both alpha values above .65 were used in further analyses. For students, Persistence at Cognitive Tasks, Social Persistence with Adults, Social Persistence 


\section{TABLE 7}

Changes in Motivation by Group (Cross-Tabulation)

\begin{tabular}{|c|c|c|c|c|}
\hline \multirow[b]{2}{*}{ Motivation change } & & \multicolumn{2}{|c|}{ Group } & \multirow[b]{2}{*}{ Total } \\
\hline & & Intervention & Control & \\
\hline \multirow[t]{3}{*}{-2.00} & Count & 0 & 1 & 1 \\
\hline & $\%$ within group & $.0 \%$ & $2.6 \%$ & $1.3 \%$ \\
\hline & $\%$ of total & $.0 \%$ & $1.3 \%$ & $1.3 \%$ \\
\hline \multirow[t]{3}{*}{-1.00} & Count & 0 & 3 & 3 \\
\hline & $\%$ within group & $.0 \%$ & $7.9 \%$ & $3.9 \%$ \\
\hline & $\%$ of total & $.0 \%$ & $3.9 \%$ & $3.9 \%$ \\
\hline \multirow[t]{3}{*}{-.50} & Count & 0 & 3 & 3 \\
\hline & $\%$ within group & $.0 \%$ & $7.9 \%$ & $3.9 \%$ \\
\hline & $\%$ of total & $.0 \%$ & $3.9 \%$ & $3.9 \%$ \\
\hline \multirow[t]{3}{*}{.00} & Count & 24 & 11 & 35 \\
\hline & $\%$ within group & $61.5 \%$ & $28.9 \%$ & $45.5 \%$ \\
\hline & $\%$ of total & $31.2 \%$ & $14.3 \%$ & $45.5 \%$ \\
\hline \multirow[t]{3}{*}{.50} & Count & 9 & 8 & 17 \\
\hline & $\%$ within group & $23.1 \%$ & $21.1 \%$ & $22.1 \%$ \\
\hline & $\%$ of total & $11.7 \%$ & $10.4 \%$ & $22.1 \%$ \\
\hline \multirow[t]{3}{*}{1.00} & Count & 5 & 9 & 14 \\
\hline & $\%$ within group & $12.8 \%$ & $23.7 \%$ & $18.2 \%$ \\
\hline & $\%$ of total & $6.5 \%$ & $11.7 \%$ & $18.2 \%$ \\
\hline \multirow[t]{3}{*}{1.50} & Count & 1 & 2 & 3 \\
\hline & $\%$ within group & $2.6 \%$ & $5.3 \%$ & $3.9 \%$ \\
\hline & $\%$ of total & $1.3 \%$ & $2.6 \%$ & $3.9 \%$ \\
\hline \multirow[t]{6}{*}{2.00} & Count & 0 & 1 & 1 \\
\hline & $\%$ within group & $.0 \%$ & $2.6 \%$ & $1.3 \%$ \\
\hline & $\%$ of total & $.0 \%$ & $1.3 \%$ & $1.3 \%$ \\
\hline & Count & 39 & 38 & 77 \\
\hline & $\%$ within group & $100.0 \%$ & $100.0 \%$ & $100.0 \%$ \\
\hline & $\%$ of total & $50.6 \%$ & $49.4 \%$ & $100.0 \%$ \\
\hline
\end{tabular}

with Children and Mastery Pleasure were used. Teacher ratings of Persistence at Cognitive Tasks, Social Persistence with Adults, Mastery Pleasure and Negative Reactions to Failure were retained.

For the student data, a repeated measures MANOVA was conducted with the two-level Within-Subject factor Time (Pre-intervention and Post-intervention), the two-level Between-Subjects factor Group (Intervention and Control), and the four DMQ subscales (Persistence at Cognitive Tasks, Mastery Pleasure, Social Persistence with Adults, and Social Persistence with Children) as the repeated measures. Assumptions were met after all measures were standardised. Box's $M$ was not significant. There was no main effect for Time or Group, and no interaction effect. Means and standard deviations for all subscales are shown in Table 8.

A repeated measures MANOVA was conducted for the teacher ratings with the two-level Within-Subject factor Time (Pre-intervention and Post-intervention), the 
TABLE 8

Means and Standard Deviations of Student-Completed DMQ Subscales

\begin{tabular}{|c|c|c|c|c|c|c|c|c|}
\hline \multirow[b]{3}{*}{ DMQ Subscale } & \multicolumn{4}{|c|}{ Control group } & \multicolumn{4}{|c|}{ Intervention group } \\
\hline & \multicolumn{2}{|c|}{$\begin{array}{l}\text { Time } 1 \\
(n=43)\end{array}$} & \multicolumn{2}{|c|}{$\begin{array}{c}\text { Time } 2 \\
(n=46)\end{array}$} & \multicolumn{2}{|c|}{$\begin{array}{c}\text { Time } 1 \\
(n=47)\end{array}$} & \multicolumn{2}{|c|}{$\begin{array}{c}\text { Time } 2 \\
(n=36)\end{array}$} \\
\hline & M & $S D$ & M & $S D$ & M & $S D$ & M & $S D$ \\
\hline Persistence at Cognitive Tasks & 3.64 & 0.55 & 3.69 & 0.58 & 3.78 & 0.68 & 3.76 & 0.51 \\
\hline Mastery Pleasure & 3.62 & 0.78 & 3.69 & 0.76 & 3.40 & 1.01 & 3.58 & 0.82 \\
\hline Social Persistence with Adults & 3.10 & 0.85 & 3.36 & 0.78 & 3.28 & 0.81 & 3.40 & 0.82 \\
\hline Social Persistence with Children & 3.69 & 0.67 & 3.70 & 0.65 & 3.80 & 0.68 & 3.66 & 0.72 \\
\hline
\end{tabular}

two-level Between-Subjects factor Group (Intervention and Control), and the three DMQ subscales (Persistence at Cognitive Tasks, Social Persistence with Adults and Negative Reaction to Failure) as the repeated measures. The Mastery Pleasure subscale was not included in the analysis as the data set violated assumptions of normality even after transformation and the omission of outliers. The exclusion of one class group resulted in unequal cell sizes (Intervention $n=46$, Control $n=22$ ), so normality of distribution, outliers and homogeneity of variance were checked carefully. All subscales were standardised and univariate outliers were excluded from the analysis. Assumptions of homogeneity of variance and covariance were met. Levene's test was not significant for any subscale and Box's M was not significant.

There was a significant effect for Group, $F(3,64)=14.10, p<.001$, Pillai's trace $=.40$, partial eta squared $=.40$, observed power $=1.0$ and a significant effect for Time, $F(3,64)=13.00, p<.001$, Pillai's trace $=.38$, partial eta squared $=.38$, observed power $=1.0$, but no significant interaction between Time and Group. Posthoc univariate analysis indicated that Social Persistence with Adults differed between groups. The Intervention group scored higher than the Control group at both pre- and post-intervention, $F(66,1)=24.55, p<.001$, partial eta squared $=.27$, observed power $=1.0$. Scores on several scales varied significantly across the two time points. There were higher scores post-intervention for Persistence at Cognitive Tasks, $F(66,1)=31.35, p<.001$, partial eta squared $=.32$, observed power $=$ 1.0; Social Persistence with Adults, $F(66,1)=5.33, p=.02$, partial eta squared $=$ .08 , observed power $=.62$; and Negative Reaction to Failure, $F(66,1)=18.79, p<$ .001 , partial eta squared $=.22$, observed power $=.99$. See Table 9 for means and standard deviations in the two groups.

\section{Discussion}

In this study, a repeated measures design was used to examine whether modifying the delivery of a school's homework program in order to better meet the theoretical components of intrinsic motivation (autonomy, relatedness and competence; Deci \& Ryan, 2008; Ryan \& Deci, 2000) would lead to more positive student attitudes to homework and whether there would be a positive change in general motivation. Although there were no overall intervention effects, it appears the intervention 
TABLE 9

Means and Standard Deviations of Teacher-Completed DMQ Subscales

\begin{tabular}{|c|c|c|c|c|c|c|c|c|}
\hline \multirow[b]{3}{*}{ DMO Subscale } & \multicolumn{4}{|c|}{ Control group } & \multicolumn{4}{|c|}{ Intervention group } \\
\hline & \multicolumn{2}{|c|}{$\begin{array}{l}\text { Time } 1 \\
(n=22)\end{array}$} & \multicolumn{2}{|c|}{$\begin{array}{c}\text { Time } 2 \\
(n=22)\end{array}$} & \multicolumn{2}{|c|}{$\begin{array}{l}\text { Time } 1 \\
(n=46)\end{array}$} & \multicolumn{2}{|c|}{$\begin{array}{c}\text { Time } 2 \\
(n=46)\end{array}$} \\
\hline & M & $S D$ & M & $S D$ & $M$ & $S D$ & $M$ & $S D$ \\
\hline Persistence at Cognitive Tasks & 2.94 & 0.61 & 3.12 & 0.71 & 3.14 & 0.59 & 3.24 & 0.65 \\
\hline Social Persistence with Adults & 2.89 & 0.54 & 3.00 & 0.55 & 3.46 & 0.55 & 3.81 & 0.60 \\
\hline Negative Reaction to Failure & 2.53 & 0.49 & 2.64 & 0.50 & 2.57 & 0.75 & 2.72 & 0.57 \\
\hline
\end{tabular}

may have had a protective effect on the motivation of students in the intervention group. Motivation in this group did not decrease across the 10 week duration of the intervention as was the case for the control group.

The Children's Attitude to Homework Questionnaire (CAHQ) had not previously been factor analysed, so an exploratory factor analysis was conducted. The three derived factors relate in a meaningful way to common perceptions about homework - that it can be a source of family conflict (Homework Conflict), that the work itself can be engaging (Homework Engagement), and that homework can be difficult (Homework Difficulty). These factors also relate to the psychological needs believed to underpin the SDT model of motivation (Deci \& Ryan, 2000). High conflict is likely to decrease feelings of relatedness while low levels of conflict does not; low engagement suggests that a task is far from intrinsically motivating, whereas high engagement suggests that the task is intrinsically motivating; and high difficulty suggests that a task is likely to decrease feelings of competence, whereas low difficulty does not.

Future revisions of the CAHQ could consider reframing some items in order to strengthen the instrument's internal consistency. Of the three derived scales, Homework Difficulty has the weakest internal consistency, and this may be due to the ambiguity of one particular item: How often does an adult help you with your homework? In order to align more strongly with the other items in the scale, this item might be rephrased as How often does an adult help you with difficulties with your homework? This wording would focus on difficulty as the cause of the help, and perhaps distinguish this help from a more positive general parental guidance. The focus would also make sense in terms of SDT, as it more clearly separates out notions of competence and relatedness (Deci \& Ryan, 2000).

There were no differences between the intervention and control groups on the three aspects of homework measured by the CAHQ, nor were there any group differences in motivation as assessed on the DMQ. Both groups of students reported a decrease in homework difficulty over time, suggesting that they became acculturated to the school's homework expectations across the timeframe of the study. Homework became easier and less challenging, and students received less help than earlier in the year. Homework difficulty links most closely with the need for competence, and it is likely that as students settle into the school year and 
become more familiar with the demands and expectations of their teachers, their feelings of competence with homework increase.

Analysis of the CAHQ homework motivation items highlights the shift to a more intrinsic style of motivation over time. This change was seen in relation to benefits of homework but was unrelated to the intervention. At the commencement of the study, the whole group mean for benefits of homework indicated a motivation style between introjected and identified, but closer to introjected. At post-intervention the group mean was closer to identified, although still falling short of the desirable integrated level of motivation. This shift in the perceived benefits of homework is not surprising given that the school strongly endorses the value of homework in school literature and information provided to students and parents.

The cross-tabulation of change in motivation against experimental grouping offers some insights into the possible processes underlying changes in motivation. For the control group, there was evidence of a wide range of change, suggesting that the school's culture and existing homework program may have been motivating for some students and demotivating for others. Interestingly, motivation was unchanged in less than one third of the control group. By contrast, the intervention group showed a different profile of motivation change across the school term. For more than half of the students there was no change in the relative strength of intrinsic motivation, and the remainder reported an increase. Notably, no students in the intervention group showed a decrease in intrinsic motivation. So it seems that the intervention may have had a protective effect on students' pre-existing levels of motivation. If continued over a longer period of time, the intervention may have enhanced homework attitudes and overall motivation.

Apart from the relatively short duration of the intervention, several other factors may have limited its effectiveness. In retrospect, we believe that the core psychological needs targeted by the intervention (autonomy, relatedness and competence) could have been met in a more comprehensive and more thoroughly curriculumintegrated way. The intervention took the form of additions, minor extensions, and 'tweaking' of the existing homework program which had been built up over time and was thoroughly integrated with the school curriculum. Katz and Assor (2007) found that students are relatively sensitive to superficial efforts to target needs, and that such efforts can be demotivating rather than motivating, and this may have been one of the factors at play here.

Another possible explanation for the non-significant findings is that there may have been some inconsistencies between the intervention as discussed and planned with teaching staff and the intervention as implemented in the classroom, even though the program was designed collaboratively with teachers. In post-intervention interviews, teachers reported not implementing some changes because they felt 'the existing program already met student needs' and because 'it would be too hard to assess all students fairly if they submitted different types of responses'. Although the goals of the intervention and the expected outcomes were discussed with individual teachers, this was done on an ad hoc basis rather than in more formal sessions that may have increased teachers' understanding and motivation for the modified homework program. The study design would have been strengthened also by the addition of measures of teacher engagement and fidelity checks on the intervention's implementation. 
Unfortunately, we were unable to take into account the perspective of parents. Although the study design included parent questionnaires at both pre- and postintervention, the response rate was so low that parent data could not be analysed. Thus, we do not know whether the intervention might have produced effects that were apparent in the home environment.

The focus of this study on boys in a private single-sex school naturally limits the generalisability of our findings. We studied male students because the research was initiated by a boys' school. Given that homework completion is more of a problem for boys than girls (Rogers \& Hallam, 2006; Xu, 2011) and that students at single-sex schools tend to be more highly engaged than those at co-educational schools (Fullarton, 2002), our intervention may have worked differently in other groups. Future research with girls, with students in co-educational schools, and with both younger and older students would be valuable for further evaluating the effectiveness of the intervention.

Despite these limitations, the current research makes an important contribution to the sparse literature about homework interventions. The study design using repeated measures, randomly assigned intervention and control groups, and multiple sources of information on each participant is sound, and the theoretical framework of self-determination theory is appropriate. We targeted the underlying psychological needs of autonomy, relatedness and competence through strategies that are supported by extensive prior research (Black \& Deci, 2000; Deci \& Ryan, 2000, 2008; Katz \& Assor, 2007; Levesque et al., 2004). Although the intervention did not improve motivation for homework or overall motivation, it did appear to have a protective effect on the quality of student motivation. Future research could build on the current study, working with schools over a longer period of time in order to develop or re-develop their homework programs from the ground up, and focusing also on engaging parents and teachers.

The findings from this study are likely to have practical value for guidance counsellors and school psychologists. Motivation is one of the most important topics in educational psychology, and a central concern for educators. In applying SDT to the problem of homework motivation, we have demonstrated a way in which theory can be translated into practice. We designed a homework intervention grounded in robust theory, and evaluated its effectiveness in a design that can be replicated or that could stimulate other intervention approaches for homework and motivation. In addition, the questionnaire measures may be useful tools for psychologists who are attempting to understand issues around homework, and the contrasting perceptions of individual students and their parents. Given the potential for homework to produce individual stress and family conflict, it is imperative that further attempts are made to create motivating, engaging homework programs that minimise the costs and give students access to the benefits that homework can bring.

\section{References}

Axelrod, M.I., Zhe, E J., Haugen, K.A., \& Klein, J.A. (2009). Self-management of ontask homework behaviour: A promising strategy for adolescents with attention and behaviour problems. School Psychology Review, 38, 325-333. 
Black, A., \& Deci, E. (2000). The effects of instructors' autonomy support and students' autonomous motivation on learning organic chemistry: A self-determination theory perspective. Science Education, 84, 740-756.

Cooper, H., Lindsay, J., Nye, B., \& Greathouse, S. (1998). Relationships among attitudes about homework, amount of homework assigned and completed, and student achievement. Journal of Educational Psychology, 90, 70-83.

Cooper, H., \& Valentine, J. (2001). Using research to answer practical questions about homework. Educational Psychologist, 36, 143-153.

Cooper, H., Valentine, J., Nye, B., \& Lindsay, J. (1999). Relationships between five after-school activities and academic achievement. Journal of Educational Psychology, 91, 369-378.

Deci, E., \& Ryan, R. (2000). The 'what' and 'why' of goal pursuits: Human needs and self-determination of behaviour. Psychological Inquiry, 11, 227-268.

Deci, E., \& Ryan, R. (2008). Facilitating optimal motivation and psychological wellbeing across life's domains. Canadian Psychology, 49, 14-23.

Frolland, J.M. (2011). Parental autonomy support and student learning goals: A preliminary examination of an intrinsic motivation intervention. Child \& Youth Care Forum, 40, 135-149.

Fullarton, S. (2002). Student engagement with school: Individual and school-level influences (Research Report No. 27). Melbourne, Australia: ACER.

Gilmore, L. (2007, September). Homework: A necessary evil? Paper presented at the APS Annual Conference, Brisbane, Australia.

Grolnick, W., Kurowski, C., \& Gurland, S. (1999). Family processes and the development of children's self-regulation. Educational Psychologist, 34, 3-14.

Haas, R., \& Reiley, K. (2008). Increasing homework completion of middle school students by using parental involvement strategies and establishing routines (Master's thesis). Saint Xavier University, Chicago, IL.

Hetherington, E. (1993). An overview of the Virginia longitudinal study of divorce and remarriage with a focus on early adolescence. Journal of Family Psychology, 7, 39-56.

Horsley, M., \& Walker, R. (2013). Reforming homework: Practices, learning and policy. Macmillan: Australia.

Katz, I., \& Assor, A. (2007). When choice motivates and when it does not. Educational Psychology Review, 19, 429-442.

Katz, I., Kaplan, A., \& Gueta, G. (2010). Students' needs, teachers' support, and motivation for doing homework: A cross-sectional study. Journal of Experimental Education, 78, 246-267.

Kohn, A. (2006). The homework myth. Why our kids get too much of a bad thing. Cambridge, MA: DeCapo Press.

Levesque, C., Zuehlke, A., Stanek, L., \& Ryan, R. (2004). Autonomy and competence in German and American university students: A comparative study based on selfdetermination theory. Journal of Educational Psychology, 96, 68-84.

Marzano, R.J., \& Pickering, D.J. (2007). Special topic: The case for and against homework. Educational Leadership, 64, 74-79.

Morgan, G.A., Busch-Rossnagel, N.A., Barrett, K.C., \& Wang, J. (2009) The Dimensions of Mastery Questionnaire (DMQ): A manual about its development, psychometrics and use. Fort Collins, CO: Human Development and Family Studies Department, Colorado State University. 
Patall, E.A., Cooper, H., \& Wynn, S. R. (2010). The effectiveness and relative importance of choice in the classroom. Journal of Educational Psychology, 102, 896-915.

Patrick, H., Kaplan, A., \& Ryan, A. (2011). Positive classroom motivational environments: Convergence between mastery goal structure and classroom social climate. Journal of Educational Psychology, 103, 367-382.

Rogers, L., \& Hallam, S. (2006). Gender differences in approaches to studying for the GCSE among high-achieving pupils. Educational Studies, 32, 59-71.

Ryan, R., \& Connell, J. (1989). Perceived locus on causality and internalization: Examining reasons for acting in two domains. Journal of Personality and Social Psychology, 57, 749-761.

Ryan, R., \& Deci, E. (2000). Self-Determination Theory and the facilitation of intrinsic motivation, social development and well-being. American Psychologist, 55, 68-78.

Theodore, L.A., Dioguardi, R.J., Hughes, T.L., Aloiso, D., Carlo, M., \& Eccles, D. (2009). A class-wide intervention for improving homework performance. Journal of Educational and Psychological Consultation, 19, 275-299.

Trautwein, U., Köller, O, Schmitz, B., \& Baumert, J. (2001). Do homework assignments enhance achievement? A multilevel analysis in 7 th-grade mathematics. Contemporary Educational Psychology, 27, 26-50.

Van Voorhis, F.L. (2011). Costs and benefits of family involvement in homework. Journal of Advanced Academics, 22, 220-249.

Vansteenkist, M., Sierens, E., Soenens, B., Luyckx, K., \& Lens, W. (2009). Motivational profiles from a self-determination perspective: The quality of motivation matters. Journal of Educational Psychology, 101, 671-688.

$\mathrm{Xu}, \mathrm{J}$. (2011). Homework completion at the secondary school level: A multilevel analysis. Journal of Educational Research, 104, 171-182. 